\title{
ニットの風合いの力学的因子
}

\author{
共立女子大学家政学部 小林 茂 雄

\section{THE MECHANICAL FACTOR ON THE HANDLE OF KNITTED FABRICS}

\section{By Shigeo Kobayashi}

(Department of Clothing Science, Kyoritsu Women's University, Hitotsubashi, Chiyoda-ku, Tokyo, Japan)

The purpose of this paper is to discuss the effect of mechanical properties on the handle of knitted fabrics. In this paper, the handle is regarded as a tactual evaluation judged from physical stimuli of fabric mechanical properties. The KES-Handle Testers were used to measure factors of mechanical properties, such as tensile, compression, bending, shear and surface characteristics. Also, the technique of factor analysis was applied to investigate relations among these mechanical factors.

As the result of factor analysis, six factors, namely, bending resistance, shear resistance, tensile resistance, tensile resilience, surface friction and surface roughness, were selected. But the factors of bending and share resistance were most important for the handle of knitted fabrics. The relation among samples are shown on the orthogonal coordinates with values of factor score. The feature of handle can be catched by the degrees of contribution of each factor to the individual sample.

(Received December 9, 1983)

\section{1. 緒 言}

布の力学的特性は强度や疲労と関連することはもち万 んでるが、このほかに風合いにとって李重要な因子で ある。すなわち，風合いは布や䋘維製品の力学的特性を 主として触覚により感賞的にとらえたもの之考えると。 風合い布の力学的特性之関連づけなからら考察するこ之 加可能である。さて，風合い関する研究は織物を中心 儿行なっれている場合が多く，二ットを対象とした研究 は少ないししかしながら，布の力学的特性の面加ら二ッ トの風合い考考慮したものとして，例えばGribson と Postle ${ }^{1)}$,丹羽 2) の報告がある。Gribson と Postle 收織 物とニットの布地について、曲げとせん断特性のパラメ 一タををとに類別を試みている。また，丹羽は外衣用二 ット地について，力学的特性のデータを集積しニット地 の特微を分析している。

本研究では伸長，曲げ，せん断，正縮变形の応力・ひ
ずみ曲線汃ら得られる力学的特性值，及びあらさ，摩擦 の表面特性の力学的特性值熖対して因子分析法を適用 し，力学的特性値の相互の関係を検討する。さらに因子 分析法により抽出された因子をあとに二ットの風合いの

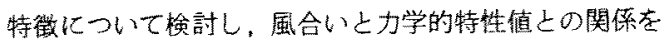
明らかにするととを目的とする。

\section{2. 力学的特性值の測定}

\section{1 試 料}

試料として約 60 点のアウトウェア用二ット布を集め たが，組織の特殊性などから実際に実験に用いたものは 46 種類である。なお，風合いの面からはドレッシィー な風合いの素材と、スポーティーな風合いの素材がほほ 半分ずつ入るように配虑した。表1亿用いた試料の概要 示吉。

\section{2 測定方法}

風合い関連する布の基本的な力学的特性として， 
Table 1 Summary of samples.

\begin{tabular}{|l|l|l|l|}
\hline \multicolumn{1}{|c|}{ Fiber } & \multicolumn{1}{|c|}{ Knit stitch } & \multicolumn{1}{c|}{ Weight } & \multicolumn{1}{c|}{ Thickness } \\
\hline Cotton $: 18$ samples, & Plain $: 15$ samples, & Under $0.02 \mathrm{~g} / \mathrm{cm}^{2}: 13$ samples, & Under $1 \mathrm{~mm}: 10$ samples, \\
Wool $: 7$ samples, & Interlock $: 5$ samples, & $0.02 \sim 0.03 \mathrm{~g} / \mathrm{cm}^{2}: 20$ samples, & $1 \sim 2 \mathrm{~mm}: 12$ samples, \\
Blended : 30 samples, & Jaquard $: 6$ samples, & Above $0.03 \mathrm{~g} / \mathrm{cm}^{2}: 13$ samples, & Above $2 \mathrm{~mm}: 24$ samples \\
Other $: 3$ samples & Other $: 20$ samples. & & \\
\hline
\end{tabular}

（1）重さ，(2)厚さ，(3) 伸長特性，(4)王縮特性，(5) 曲げ特性，(6)女九断特性，(7)表面特性の因子があげ られている゙ぜ。これらの因子の測定は，主としてKES 風合いシステムの測定機に上り行なった。測定条件の概 要は次化示す通りでる。

(1) 重さ

$\mathrm{g} / \mathrm{cm}^{2}$ の值でホした。

(2) 原 巳

KES-FB 3 E鍢試験譏で測定した。すなわち，0.5g $/ \mathrm{cm}^{2}$ の荷重下での值である。

(3) 伸長特性

KES-FB 1 伸長・せん断試駼機で測定した。すなお 与、有効試料長は長さ $5 \mathrm{~cm} \times$ 幅 $20 \mathrm{~cm}$ であり，最大伸長 荷重 $500 \mathrm{~g} / \mathrm{cm}$ の定荷伸長に括いて, 伸長応力・ひする 曲線を測定した。。の曲線加ら伸長特性の測定値 ${ }^{6)}$ とし

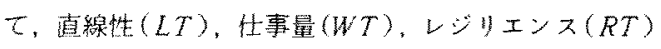
存めた。

\section{(4) 生艘特性}

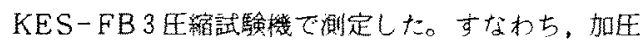
丹面皘 $2 \mathrm{~cm}^{2}$ のもとで，最大正縮荷重 $50 \mathrm{~g} / \mathrm{cm}^{2}$ の定荷 重区縮に求いて，代縮応力・ひずみ曲線を測定した。て の曲線加的縮特性の測定値 ${ }^{5)}$ として, 直線性 $(L C)$ 。 仕事量 $(W C)$ ，レジリエンス $(R C)$ ，仕縮率 $(E M C)$ を 求め大。

(5) 曲状特性

KES-FB 2 純曲牧試験機で測定した。すなわち，有 効試料長は長さ $20 \mathrm{~cm} \times$ 幅 $1 \mathrm{~cm}$ であり、最大曲率 2.5 $\mathrm{cm}^{-1}$ のむとで，曲げモーメント・曲率曲線を測定した。 この曲線汃ら曲状特性の測定值 ${ }^{5)}$ として，上ステリシス 幅 $(2 H B)$ ，風性 $(B)$, 曲代モーメント $(L B)$ 在求めた。 との場合，ヒステリシス幅は曲率 $0.5 \mathrm{~cm}^{-1}, 1.5 \mathrm{~cm}^{-1}$. $2.5 \mathrm{~cm}^{-1}$ のとき，剛性は曲率 $1 \mathrm{~cm}^{-1}$ のとき，曲げモ一 メントは曲率 $2.5 \mathrm{~cm}^{-1}$ のときの値を求めた。

(6) 甘九断特性

KES-FB 1 伸長・世九断試駼機で測定した。すなわ 与, 有効試料長は長さ $5 \mathrm{~cm} \times$ 幅 $20 \mathrm{~cm}$ であり，最大せん 断角 $8^{\circ}$ の定ひずみせん断において，せん断席力・ひずみ 曲線老測定した。この曲線加ら世九断特性の測定值 ${ }^{\text {(2) }}$ 之 して，ヒステリシス幅 $(2 H G)$ ，薊性 $(G)$ ，世九断応力 ( $L G)$ 在求めた。この場合，ヒステリシス幅はせ九断角 $0.5^{\circ} ， 3^{\circ} ， 5^{\circ}$ のとき，剛性は甘ん断角 $3^{\circ}$ のとき，甘ん断 応力はせん断角 $8^{\circ}$ のときの值求めた。

(7) 表面特性

KES-FB 4 䒾面試験機で測定した。すなわち，摩擦 曲線及び粗さ曲線を測定し，乙の曲線加引表面特性の㯕 定值 ${ }^{6)}$ 上して, 平均摩摖保数 (MIU)，摩擦保数の平均徧 差 $(M M D)$ ，表面粗さの平均偏差 $(S M D)$ を求めた。 お、摩擦特性值の测定の場台、摩擦子は $0.5 \mathrm{~mm} \phi$ のピ ノ線を 10 本亚べたもので摩擦子の大きさは長さ $0.5 \mathrm{~cm}$ ×幅 $0.5 \mathrm{~cm}$, 摩擦子王 $50 \mathrm{~g}$ である。一方，粗さ特性值 の測定の場合，接触子は $0.5 \mathrm{~mm} \phi$ の字形ピアノ線であ り，接触子王は $10 \mathrm{~g}$ である。

\section{3 測定結果}

全試料の各測定值は膨大になるために，表2に力学的 特性值の最大佰, 最小值, 平均值, 標準编差示した。

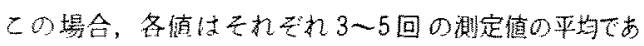
る。なお，先の測定方法の項でよりあげた特性値のうち， 曲げモーメント，曲げヒステリシス幅(曲率 $1.5 \mathrm{~cm}^{-1}$ ， $\left.2.5 \mathrm{~cm}^{-1}\right)$ ，女九断応力，女九断七ステリシス辐 $\left(5^{\circ}\right)$ の 測定值は省略している。これは曲げモーメントや应力に ついては，一部の試料化計测不可能なるのがあったたか， またヒステリシス幅については他の条件のヒステリシス 幅之ほほ同傾向を示したためである。測定は46陚料仡 ついて行なったが，試料の一部に厚すきて曲げの則定が 不可能なももがあったために，表の㰾定值は 41 試料に つネての值である。

\section{3. 力学的因子による風合いの考察}

\section{1 因子分析法による力学的因子の抽出}

力学的特性值間の関保を明らか比するため，因子分析 法老適用して検討した。すな⿰七口，表2の39項目の力学 的特性について，相関保数行列をむとに主因子解法に上 り因子負荷量を求めた。表 3 はバリマックス回転後の团 子負荷量を示したものである。

第 1 过子 $\left(a_{1}\right)$ 加ら第 6 因子 $\left(a_{b}\right)$ まで因子抽出したが， この場合の累積因子寄与率は $83.6 \%$ に達している。 た，各力学的特性の共通性 (Communality) $h^{2}$ は，例元 次 No. 28 伸長特性の仕事量 (タテ) 0.44 の上う小さな 值を有するものもあるが，大部分は大きな值を有しはば 因子の抽出加終っているとみなすととができる。剈因子 
Table 2 Measurement of mechanical property.

\begin{tabular}{|c|c|c|c|c|c|c|}
\hline No. & & Mechanical property & Mean & $\begin{array}{l}\text { Standard } \\
\text { deviation }\end{array}$ & Maxi. & Mini. \\
\hline 1 & \multicolumn{2}{|r|}{ Weight $\left(\mathrm{g} / \mathrm{cm}^{2}\right) \times 10^{-4}$} & 239 & 73 & 608 & 122 \\
\hline 2 & \multicolumn{2}{|r|}{ Thickness $(\mathrm{cm}) \times 10^{-1}$} & 1.76 & 0.79 & 4.11 & 0.58 \\
\hline 3 & \multirow{4}{*}{ 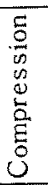 } & $L C$ & 0.347 & 0.071 & 0.531 & 0.249 \\
\hline 4 & & $W C\left(\mathrm{~g} \cdot \mathrm{cm} / \mathrm{cm}^{2}\right)$ & 0.699 & 0.427 & 1.937 & 0.150 \\
\hline 5 & & $R C(\%)$ & 44.0 & 8.1 & 57.9 & 24.0 \\
\hline 6 & & $E M C(\%)$ & 39.4 & 7.8 & 56.3 & 23.1 \\
\hline 7 & \multirow{9}{*}{$\frac{\bar{\sigma}}{\stackrel{\Xi}{\sim}}$} & $G$, warp $(\mathrm{g} / \mathrm{cm} \cdot \mathrm{deg})$ & 0.612 & 0.222 & 1.211 & 0.263 \\
\hline 8 & & $G$, weft $(\mathrm{g} / \mathrm{cm} \cdot \mathrm{deg})$ & 0.613 & 0.218 & 1.122 & 0.278 \\
\hline 9 & & $G$, mean $(\mathrm{g} / \mathrm{cm} \cdot \mathrm{deg})$ & 0.613 & 0.217 & 1.086 & 0.270 \\
\hline 10 & & $2 H G 0.5$, warp $(\mathrm{g} / \mathrm{cm})$ & 1.91 & 0.69 & 5.65 & 0.78 \\
\hline 11 & & $2 H G 0.5$, weft $(\mathrm{g} / \mathrm{cm})$ & 1.83 & 0.73 & 4.43 & 0.76 \\
\hline 12 & & $2 H G 0.5$, mean $(\mathrm{g} / \mathrm{cm})$ & 1.87 & 0.70 & 5.04 & 0.79 \\
\hline 13 & & $2 H G 3$, warp $(\mathrm{g} / \mathrm{cm})$ & 1.97 & 0.73 & 5.58 & 0.80 \\
\hline 14 & & $2 H G 3$, weft $(\mathrm{g} / \mathrm{cm})$ & 1.83 & 0.75 & 4.36 & 0.78 \\
\hline 15 & & $2 H G 3$, mean $(\mathrm{g} / \mathrm{cm})$ & 1.90 & 0.72 & 4.97 & 0.80 \\
\hline 16 & \multirow{9}{*}{ 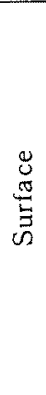 } & $M I U$, warp & 0.295 & 0.105 & 0.676 & 0.166 \\
\hline 17 & & $M I U$, weft & 0.323 & 0.104 & 0.680 & 0.196 \\
\hline 18 & & $M I U$, mean & 0.309 & 0.100 & 0.678 & 0.181 \\
\hline 19 & & $M M D$, warp & 0.0168 & 0.0083 & 0.0445 & 0.0077 \\
\hline 20 & & $M M D$, weft & 0.0236 & 0.0109 & 0.0464 & 0.0091 \\
\hline 21 & & $M M D$, mean & 0.0200 & 0.0077 & 0.0374 & 0.0098 \\
\hline 22 & & $S M D$, warp (micron) & 6.85 & 3.77 & 18.32 & 2.49 \\
\hline 23 & & $S M D$, weft (micron) & 10.05 & 6.38 & 26.86 & 3.24 \\
\hline 24 & & $S M D$, mean (micron) & 8.45 & 4.37 & 22.59 & 2.90 \\
\hline 25 & \multirow{9}{*}{$\begin{array}{l}\stackrel{\oplus}{\bar{D}} \\
\stackrel{\omega}{\oplus}\end{array}$} & $L T$, warp & 0.62 & 0.09 & 0.87 & 0.49 \\
\hline 26 & & $L T$, weft & 0.52 & 0.08 & 0.68 & 0.34 \\
\hline 27 & & $L T$, mean & 0.57 & 0.07 & 0.75 & 0.45 \\
\hline 28 & & $W T$, warp $\left(\mathrm{g} \cdot \mathrm{cm} / \mathrm{cm}^{2}\right)$ & 29.94 & 9.74 & 54.15 & 7.85 \\
\hline 29 & & $W T$, weft $\left(\mathrm{g} \cdot \mathrm{cm} / \mathrm{cm}^{2}\right)$ & 58.48 & 23.43 & 13275 & 6.20 \\
\hline 30 & & $W T$, mean $\left(\mathrm{g} \cdot \mathrm{cm} / \mathrm{cm}^{2}\right)$ & 44.21 & 14.32 & 92.60 & 8.13 \\
\hline 31 & & $R T$, warp $(\%)$ & 35.42 & 9.43 & 57.01 & 22.00 \\
\hline 32 & & $R T$, weft $(\%)$ & 3283 & 8.66 & 54.84 & 19.83 \\
\hline 33 & & $R T$, mean $(\mathscr{\%})$ & 34.12 & 8.37 & 50.53 & 20.92 \\
\hline 34 & \multirow{6}{*}{$\frac{\not}{\stackrel{D}{\Xi}}$} & $B$, warp $\left(\mathrm{g} \cdot \mathrm{cm}^{2} / \mathrm{cm}\right)$ & 0.077 & 0.059 & 0.228 & 0.009 \\
\hline 35 & & $B$, weft $\left(\mathrm{g} \cdot \mathrm{cm}^{2} / \mathrm{cm}\right)$ & 0.052 & 0.049 & 0.227 & 0.003 \\
\hline 36 & & $B$, mean $\left(\mathrm{g} \cdot \mathrm{cm}^{2} / \mathrm{cm}\right)$ & 0.065 & 0.049 & 0.163 & 0.007 \\
\hline 37 & & $2 H B 0.5^{-1},(\mathrm{~g} \cdot \mathrm{cm} / \mathrm{cm})$ & 0.068 & 0.051 & 0.325 & 0.009 \\
\hline 38 & & $2 H B 0.5^{-1},(\mathrm{~g} \cdot \mathrm{cm} / \mathrm{cm})$ & 0.047 & 0.038 & 0.160 & 0.005 \\
\hline 39 & & $2 H B 0.5^{-1},(\mathrm{~g} \cdot \mathrm{cm} / \mathrm{cm})$ & 0.058 & 0.041 & 0.208 & 0.008 \\
\hline
\end{tabular}


Table 3 Factor loading matrix.

\begin{tabular}{|c|c|c|c|c|c|c|c|}
\hline No. & $a_{1}$ & $a_{2}$ & $a_{3}$ & $a_{4}$ & $a_{6}$ & $a_{6}$ & $h^{2}$ \\
\hline 1 & 0.78 & 0.13 & -0.20 & -0.12 & 0.20 & -0.22 & 0.77 \\
\hline 2 & 0.78 & -0.18 & 0.03 & -0.48 & -0.04 & 0.02 & 0.87 \\
\hline 3 & 0.49 & 0.06 & 0.04 & -0.69 & -0.07 & -0.18 & 0.76 \\
\hline 4 & 0.63 & -0.32 & 0.19 & -0.54 & -0.16 & 0.09 & 0.86 \\
\hline 5 & 0.11 & -0.35 & 0.27 & -0.16 & 0.17 & -0.62 & 0.65 \\
\hline 6 & -0.10 & -0.51 & 0.47 & 0.03 & -0.34 & 0.38 & 0.74 \\
\hline 7 & -0.01 & 0.84 & 0.15 & 0.25 & 0.27 & -0.22 & 0.91 \\
\hline 8 & 0.06 & 0.89 & 0.13 & 0.24 & 0.17 & -0.17 & 0.93 \\
\hline 9 & 0.03 & 0.87 & 0.14 & 0.25 & 0.23 & -0.20 & 0.94 \\
\hline 10 & 0.04 & 0.80 & 0.06 & -0.18 & -0.16 & 0.47 & 0.93 \\
\hline 11 & 0.23 & 0.84 & -0.01 & -0.14 & -0.03 & 0.42 & 0.96 \\
\hline 12 & 0.14 & 0.84 & 0.03 & -0.17 & -0.10 & 0.45 & 0.97 \\
\hline 13 & 0.07 & 0.86 & 0.05 & -0.17 & -0.14 & 0.38 & 0.94 \\
\hline 14 & 0.24 & 0.86 & 0.01 & -0.12 & -0.06 & 0.38 & 0.95 \\
\hline 15 & 0.16 & 0.87 & 0.03 & -0.15 & -0.10 & 0.39 & 0.97 \\
\hline 16 & 0.23 & 0.10 & -0.11 & -0.89 & -0.23 & 0.03 & 0.92 \\
\hline 17 & 0.29 & 0.07 & -0.36 & -0.78 & -0.03 & 0.07 & 0.83 \\
\hline 18 & 0.27 & 0.09 & -0.25 & -0.88 & -0.14 & 0.05 & 0.93 \\
\hline 19 & -0.08 & 0.06 & -0.43 & -0.58 & -0.44 & -0.01 & 0.71 \\
\hline 20 & 0.07 & 0.03 & -0.86 & 0.09 & -0.02 & 0.26 & 0.83 \\
\hline 21 & -0.00 & 0.03 & -0.85 & -0.27 & -0.26 & 0.19 & 0.90 \\
\hline 22 & -0.04 & -0.22 & -0.59 & -0.22 & -0.49 & -0.03 & 0.69 \\
\hline 23 & 0.19 & -0.18 & -0.85 & -0.04 & 0.03 & 0.18 & 0.82 \\
\hline 24 & 0.12 & -0.23 & -0.87 & -0.12 & -0.19 & 0.11 & 0.89 \\
\hline 25 & 0.37 & 0.20 & -0.38 & 0.46 & -0.01 & -0.18 & 0.57 \\
\hline 26 & 0.08 & 0.61 & -0.21 & 0.54 & -0.12 & -0.18 & 0.76 \\
\hline 27 & 0.27 & 0.46 & -0.35 & 0.57 & -0.07 & -0.20 & 0.77 \\
\hline 28 & -0.19 & 0.20 & 0.16 & -0.01 & 0.58 & -0.04 & 0.44 \\
\hline 29 & -0.12 & -0.13 & 0.07 & 0.19 & 0.87 & 0.04 & 0.84 \\
\hline 30 & -0.17 & -0.04 & 0.11 & 0.15 & 0.91 & 0.02 & 0.90 \\
\hline 31 & 0.04 & -0.12 & 0.10 & 0.17 & -0.00 & -0.89 & 0.84 \\
\hline 32 & -0.07 & -0.15 & 0.19 & -0.05 & -0.11 & -0.85 & 0.80 \\
\hline 33 & -0.01 & -0.15 & 0.15 & 0.07 & -0.06 & -0.94 & 0.93 \\
\hline 34 & 0.90 & 0.17 & -0.16 & -0.05 & 0.02 & 0.03 & 0.88 \\
\hline 35 & 0.76 & 0.03 & 0.03 & 0.01 & -0.45 & -0.17 & 0.80 \\
\hline 36 & 0.93 & 0.12 & -0.08 & -0.02 & -0.21 & -0.06 & 0.93 \\
\hline 37 & 0.84 & 0.19 & -0.15 & -0.13 & 0.08 & 0.19 & 0.82 \\
\hline 38 & 0.77 & 0.14 & 0.06 & -0.07 & -0.41 & 0.07 & 0.80 \\
\hline 39 & 0.88 & 0.19 & -0.07 & -0.12 & -0.14 & 0.15 & 0.88 \\
\hline$\sum a_{i}^{2}$ & 6.94 & 8.12 & 4.60 & 4.92 & 3.45 & 4.54 & 32.62 \\
\hline $\begin{array}{l}\text { Proportion of } \\
\text { total variance }(\mathscr{O})\end{array}$ & 17.8 & 20.8 & 11.8 & 12.6 & 8.8 & 11.6 & 83.6 \\
\hline
\end{tabular}


加ら $a_{6}$ 因子がそ扎ぞれ何を意味するかについて考察す る。c口婸合，因子負荷量の大きさを比較する一つ目 安として，絶対值 0.75 以上の項目に注目してみる。第 1

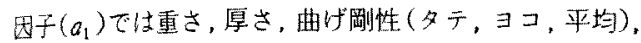
曲げヒステリシス幅(タテ、ヨコ，平均)の各測定項目か あけられる。とれらの測定填目加的第 1 因子 $\left(a_{1}\right)$ の意 昧点考えると，曲げ抵抗性に関する性算を表わす因子と みなすとができる。

第2因子 $\left(a_{2}\right)$ については，せん断剛性（タテ，ヨコ， 平均)，せん断七ステリシス幅 0.5（タテ、ヨコ，平均）， せん断七ステリシス幅 3(タテ，ヨコ，平均)があげられ る。てれらの測定項目加ら第 2 因子 $\left(a_{2}\right)$ はせん断抵抗性 を表わす因子よみなすとができる。以下，同様にして 各因子の意味を考察する之，第 3 囚子 $\left(a_{3}\right)$ は表面粗さの 性賈、第 4 团子 $\left(a_{4}\right)$ は表面摩擦の性䝯，第 5 日子 $\left(a_{b}\right)$ は伸長抵抗性の性質，第6因子 $\left(a_{6}\right)$ は伸長回復性 0 性 質を表わす因子みなすととができる。

これらの6因子，すふわら，曲げ抵抗性，士ん断抵抗 性，表面粗さ，表面摩擦，伸長抵抗性，伸長回復性は， ニット布の力学的特性にとって重要な因子であるといえ る。このなかでも，特にせん断抵抗性と曲げ抵抗性は重 要な因子であることが，因子笴与率の割合からわかる。 また，伸長特性加らは抵抗性之回復性の2つ0因子加抽 出されたが，正縮性は特徽的な因子として抽出されてい

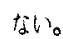

\section{2 因子得点による風合いの考察}

因子分析により抽出された力学的因子に齐して，各試

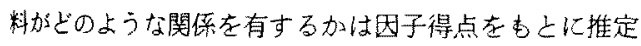
できる。图1〜四3は2因子ずつ組合わせ，平面座標上 に各試料を四六したあのである。との場合，力学的特性 の基本的なすのとして重ざをとりあげ，区中のプロット 点を重さの程度により区別して示した。なお，各四にお いて座標軸の方向性の意味は次の通りである。 $a_{1}$ 軸では プラス則が曲げ抵抗生大，マイナス側が曲げ抵抗性小， $a_{2}$ 軸ではプラス側がせん断抵抗性大，マイナス側がせん 断抵抗性小， $a_{3}$ 朝ではプラス側が粗さ小，マイナス側が 粗さ大， $a_{4}$ 軸ではブラス側か摩擦小，マイナス側が摩擦 大， $a_{5}$ 軸ではプラス則が伸長抵抗性大，マイナス側が伸 長抵抗性小， $a_{6}$ 軸ではプラス側が伸長回復性小，マイナ ス側加伸長回復性大に相当する。また，各プロット点の 数字は試料番号であり，図 2 中の丸四の数字は起毛加工 有を示している。

重さとの関連で各図を考察すると，図1にみられるよ うに曲げ抵抗性の大小は重さと関連しているが，他の因 子の場合には明確な特長はみられない。また，曲げ抵抗 生と甘ん断抵抗性を組合わせて考えると，曲げ抵抗性及

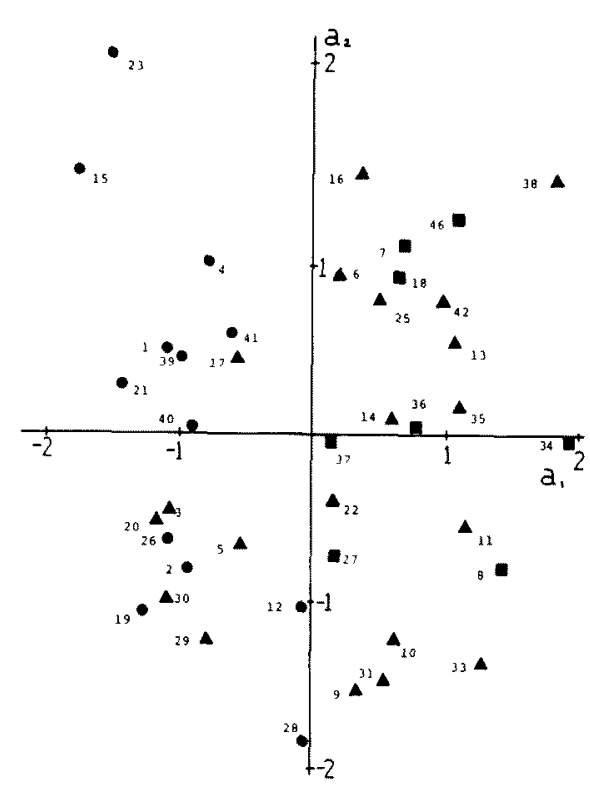

Fig. 1 Distribution of knitted fabrics by factor scores of factor $a_{1}$ and $a_{2}$.

: Under $0.02 \mathrm{~g} / \mathrm{cm}^{2}$

A : $0.02 \sim 0.03 \mathrm{~g} / \mathrm{cm}^{2}$

口 : Above $0.03 \mathrm{~g} / \mathrm{cm}^{2}$

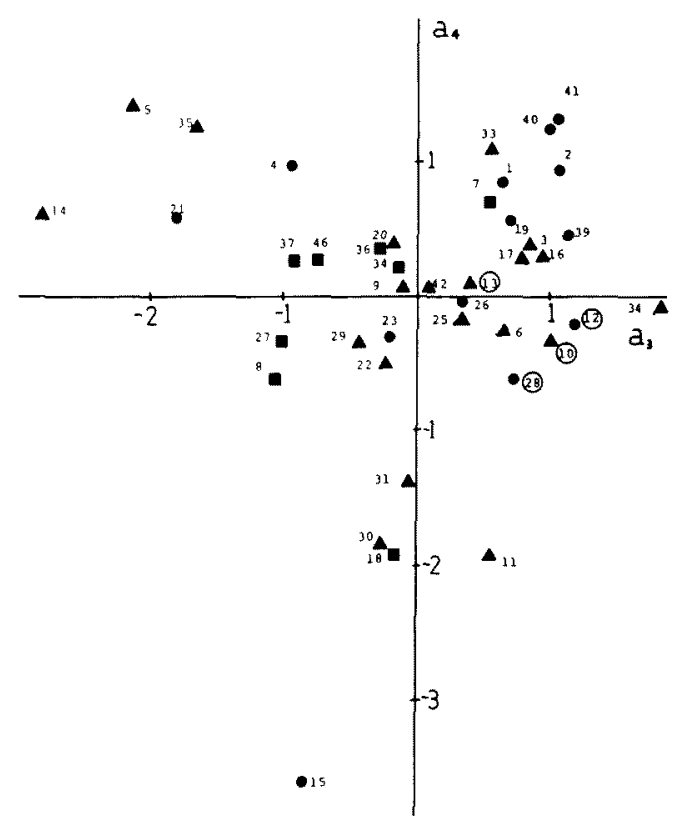

Fig. 2 Distribution of knitted fabrics by factor scores of factor $a_{3}$ and $a_{4}$. 
びせん断抵抗性がともに大きい試料は重さが大であり， 逆によ屯に小さい試料は重さが小の傾向がみられる。な 招，厚さとの関連からも同様の考察を試みたが、重さの 坦合上ほほ同じ傾问が得られた。

次に二ット有の風合いとして，硬軟感，平滑感，かさ 高感，弾力感をとりあげ，䋐維関係の仕事にたずさわっ

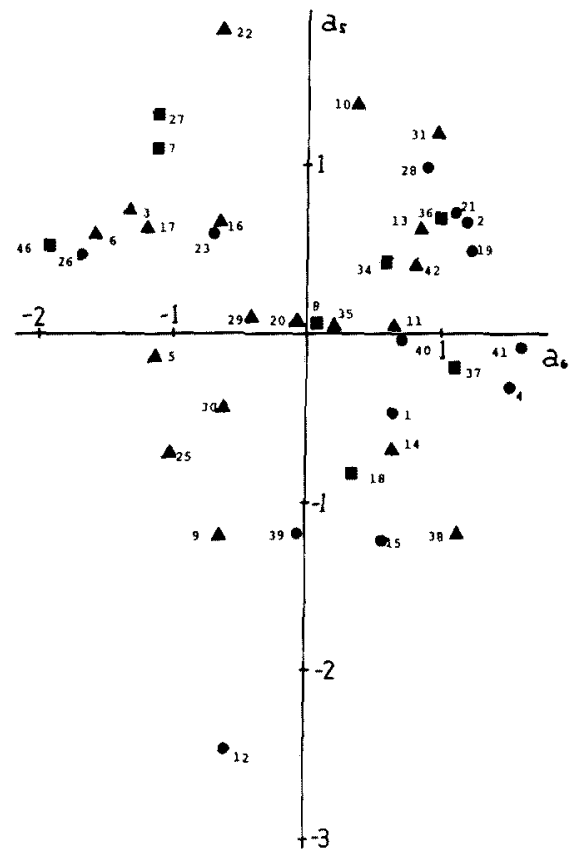

Fig. 3 Distribution of knitted fabrics by factor scores of factor $a_{5}$ and $a_{6}$.
ている専閶家 7 人に，5段階尺度で評価してすらった。 評価の平均值により試料を分類すると表 40ようになる 表中の数字は試料番号であり，前述の図1〜図3中の試 料番号と対応している。

風合い評洒の結果では，硬軟感上弾力感にはある程度 の相関がみられ，柔らかい試料は弾力感がなく，としか ないと評価されや古い。風合い上力学的因子の関係儿つ

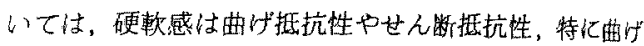
技抗性已関連している。しかしながらっこれらの因子よ 対地しない試料ああり，乙れは今回の因子分析では抽出 されなかったが，王縮性の因子の影響ではないかと思わ れる。平滑感については粗さや摩擦，特に粗さの因子亡 ある程度関軽がある。しかしながら、ニット布の場合に は、表值形態が編組織により大きく異なり，また複䧺で あるために，粗さや摩擦の因子上一致しない試料むかな り存在する。加さ高感については，抽出された物理的因 子というよりは厚さによりほ蛋決まるようである。この 点に関しては Brown ${ }^{6)}$ の研究結果とも一致している。 た，弾力感については，曲り゙抵抗性と関連しているが， これは編組轼がしっからしていて弾力感のある試料は， 抵抗性む大きい試料と一致するためと思われる。伸長性 の因子とは対応する風合い評価がなかったが，てれは風 合いの評価項目に伸長性の官能噇がなかったためである う。全体を通して二ット布の場合には，織物に比べて編 織織により表面状態や厚さなどが大きく变化するために， 風合い評価量のレベルがかなり大輻汇変化するようで る。

\section{4. 結言}

ニット布の力学的特性值をもよに風合いについて㛟討

Table 4 Assessment of handle.

\begin{tabular}{|c|c|c|c|c|}
\hline $\begin{array}{l}\text { Subjective } \\
\text { assessment }\end{array}$ & $\underset{1 \text { score }}{1}$ Small & & & Large $\longrightarrow$ \\
\hline Softness & $\begin{array}{l}1,2,3,4,19,20 \\
21,26,40\end{array}$ & $\begin{array}{l}15,17,22,23,28 \\
29,39,41\end{array}$ & $\begin{array}{l}5,6,8,9,10,12, \\
16,25,27,30,31, \\
33,36,37,42\end{array}$ & $\begin{array}{l}7,11,13,14,18 \\
34,35,38,46\end{array}$ \\
\hline Smoothness & $\begin{array}{l}1,2,3,10,19 \\
28,40,41\end{array}$ & $\begin{array}{l}4,6,7,13,16, \\
17,23,25,33,38, \\
39,42\end{array}$ & $\begin{array}{r}5,12,20,21,22, \\
26,29,34,35,36 \\
37\end{array}$ & $\begin{array}{r}8,9,11,14,15 \\
18,27,30,31,46\end{array}$ \\
\hline Bulkiness & $\begin{array}{r}1,2,3,4,19,20 \\
21,23,26,40,41\end{array}$ & $\begin{array}{l}5,7,12,14,15, \\
17,22,29,30,35, \\
36,37,39,42\end{array}$ & $\begin{array}{r}6,9,16,18,25 \\
27,31,33,34,46\end{array}$ & $\begin{array}{r}8,10,11,13,28 \\
38\end{array}$ \\
\hline Resilience & $\begin{array}{l}1,2,19,21,23 \\
26,31,36,40,41 \\
42\end{array}$ & $\begin{array}{l}3,4,8,15,17 \\
18,20,22,27,30 \\
33,35,39\end{array}$ & $\begin{array}{r}5,6,7,14,16, \\
25,28,29,34,38\end{array}$ & $\begin{array}{l}9,10,11,12,13 \\
37,46\end{array}$ \\
\hline
\end{tabular}


した結果，次のととが明らかになった。

ニット布の力学的特性值は，区子分析に上り6因子に まとめるととができる。れらの因子は曲げ抵抗性，世 九断抵洼性，伸長抵抗性，伸長回復性，表面粗さ，表面 摩擦へ因子である。

因子得点による試料の布垡状態をもとに，硬軟感，平 滑感，加高感，弾力感の風合い評価と力学的因子の関 保考察した結果, 硬軟感や弾力感は曲げ抵抗性及びせ 九断抵抗性，平滑感は表面粗さ及び表面摩摖，かさ高感 は愿さとある程度の関連がみられる。しかしながら、二 ット布の場合には、編織織により表面状態や厚さなどが 大きく変化するために，力学的因子上対応しない試料委 存在する。
付記：本研究の一部は瀻維学会昭和 58 年度年次大会 研究発表会において発表した。

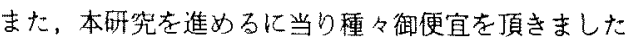
日本メリヤス椎查協会，鼠津亨技術部長に感謝致します。

\section{文献}

1) V. L. Gibson and R. Postle; Text. Res. J., 48, 14 (1978)

2)丹羽雅子; 紻機誌, 29, P 198 (1976)

3）小林茂雄; 緎機誌, 26, P 88 (1973)

4) 川端秀雄；緎機誌，26，P 721 (1973)

5）川端秀雄；緎機誌，33，P 136 (1980)

6) P. Brown; Text. Res. J., 39, 395 (1969) 